\title{
SALGADO, O INESPERADO: O BRASIL NOS QUATRO ROMANCES DE PLÍNIO SALGADO
}

Flávio Aguiar ${ }^{1}$

fwaguiar@usp.br

RESUMO: Este artigo situa, em primeiro lugar, a trajetória biográfica e política de Plínio Salgado, o líder do Integralismo brasileiro. A seguir. descreve e analisa seus quatro romances, caracterizando-os dentro do panorama da década de 30 no Brasil e seu papel no projeto político do autor. A análise também aborda a crítica social que o autor faz à sociedade brasileira do tempo.

Palavras-chave: Plinio Salgado; romance; Integralismo

Nihil humani a me alienum puto. Máxima preferida de Karl Marx, citando, no álbum de poesia de sua filha Jenny, uma frase de Terêncio.

Plínio Salgado foi o principal líder da Açāo Integralista Brasileira, movimento de extrema direita, inspirado, em parte, no fascismo italiano, que empolgou parte da juventude e da intelectualidade brasileira durante a década de 1930. Foi jornalista. Era considerado um orador brilhante e, além de publicar dezenas de livros políticos e religiosos, foi também escritor literário de sucesso. Publicou quatro romances e alguns livros de poemas, contos e crônicas. A fama do político,

1 Professor aposentado da FFLCH da Universidade de Sāo Paulo 
no entanto, sufocou, ao longo do tempo, o renome do escritor. Estigmatizado o autor como de "extrema direita" e como "fascista" a obra literária mergulhou num injustificado ostracismo de público e critica (com raras exceções). Entretanto, devese assinalar que seu livro Vida de Jesus, publicado em 1942, alcançou até hoje mais de vinte reediçōes ou reimpressōes e, se não é um best-seller, tem lugar de destaque nas seções de Religião em algumas das maiores livrarias do pais.

Plínio Salgado nasceu em 22 de janeiro de 1895, na cidade de São Bento do Sapucaí, estado de São Paulo, na regiāo brasileira hoje conhecida como "Sudeste" então simplesmente "Sul" Morreu na cidade de São Paulo, em 8 de dezembro de 1975, depois de ter sido deputado federal de 1963 a 1974 , primeiro pelo estado do Paraná e depois, a partir de 1963, por seu estado natal, São Paulo.

Quando nasceu, o Brasil abolira a escravidão havia menos de sete anos e era uma Repüblica havia menos de seis. Era um pais predominantemente agro-exportador, sobretudo de café; mais de $70 \%$ da população habitava regiões rurais. A integração do território nacional, sob a hegemonia do governo central, no Rio de Janeiro, era ainda débil. No extremo sul do Brasil, rebeldes federalistas contestavam o governo central, numa sangrenta revolta que, em três anos (1893-1895), provocou mais de dez mil mortes, mil pela degola de prisioneiros, de parte a parte. Os rebeldes chegaram a constituir um governo provisório na cidade de Nossa Senhora do Desterro, capital do Estado de Santa Catarina. Reconquistada pelas tropas legalistas em meio a uma sangrenta repressão, com execuçōes por fuzilamento ou na forca, na fortaleza de Anhatomirim, ela foi rebatizada em seguida como cidade de Florianópolis, em homenagem a Floriano Peixoto, o Marechal de Ferro. Nos sertōes do Norte, massas de camponeses empobrecidos, de ex-escravos expulsos das terras dos senhores. de bandoleiros em busca de refúgio, reuniam-se sob a liderança religiosa do beato Antonio Conselheiro no arraial de Canudos, rebatizado como Belo Monte, em terras do estado 
da Bahia. Revoltados, esses camponeses, depois de uma tenaz resistência, foram praticamente exterminados por forças do Exército Nacional e de milícias estaduais, em 1897

Em 1975, quando Plínio Salgado morreu, a maioria da população brasileira (cerca de $70 \%$ ) vivia em regiões urbanas. Embora extensas regiōes fossem ainda relativamente pouco habitadas, o Brasil era um país industrializado, sobretudo no Sudeste e no Sul. Seus mais distantes rincōes já eram atingidos por redes nacionais de televisão e de rádio. Um governo autoritário - como o do Marechal de Ferro - de forte base nos quartéis, mas também com apoio expressivo dos civis de direita, entre os quais Plínio Salgado - dominava o país desde o golpe militar de 1964, que derrubara o presidente eleito João Goulart e promovera violentas perseguiçōes contra militantes de esquerda, opositores liberais, estudantes, operários, camponeses, intelectuais, artistas e jornais dissidentes. Deve-se dizer que, no ano de 1975, o cerne do regime militar - o "sistema" como então se dizia - já dava os primeiros sinais de isolamento e de dificuldades para conter as oposiçōes. $\mathrm{O}$ alcance político destas cresceria até a queda, ou melhor, o esfacelamento da "ditadura", dez anos mais tarde, em 1985, com sua substituição por um governo civil, ainda que eleito indiretamente.

Nas décadas de 20 e 30 , ao mesmo tempo em que se firmava o direito da arte à experimentação, todo o campo da cultura passou por um grande processo de politização. O Brasil, antes frequentemente definido como um país pitoresco, pobre, porém afortunado, passou muitas vezes a ser apresentado como um país atrasado e subdesenvolvido. E os romances de Plínio Salgado também participaram dessa redefinição do perfil nacional.

Pelo lado materno, Plínio Salgado descendia de Pero Dias, um dos fundadores da cidade de São Paulo, no século XVI. O ambiente familiar era católico, nacionalista, letrado e conservador. Seu pai era farmacêutico mas, na verdade, o chefe político da cidade; admirava o Marechal de Ferro. A mãe era 
professora e dava aulas na Escola Normal da cidade, o que, na época, era uma distinção.

A morte prematura do pai forçou-o a trabalhar a partir dos 18 anos. Foi professor, agrimensor, jornalista e desenvolveu atividades de liderança nas iniciativas culturais em sua cidade natal. Em 1918 casou-se com Dona Maria Amália Pereira. Pouco depois nasceu uma filha do casal mas, em seguida, Dona Maria Amália morreu, quando a menina ainda não completara um mês. Plínio Salgado mergulhou numa profunda crise existencial. Melhorou através do mergulho na religião católica - fato que seria marcante tanto em sua vida política como na de escritor.

Na década de 20, Salgado mudou-se para a capital do estado, onde desenvolveu principalmente atividades literárias. A cidade era o palco privilegiado das atividades dos grupos de vanguarda no Brasil, ao mesmo tempo em que cresciam nela as atividades industriais e os bairros operários, com a imigraçāo européia, sobretudo a de italianos, que trouxeram os movimentos anarquistas.

Plinio Salgado via as propostas da vanguarda artística com alguma desconfiança, assinalando que, em paises cujos povos eram frágeis do ponto de vista cultural - e este seria o caso do Brasil, país ainda em formação - os principios da arte moderna poderiam ser mais danosos do que benéficos. Entretanto, isto não impediu que em seu primeiro romance - $O$ Estrangeiro - publicado em 1926, adotasse um estilo marcado por "vanguardismos": uma prosa fragmentária, organizada em instantâneos descontínuos, com variaçōes dramáticas de pontos de vista. O romance foi um sucesso: em menos de um mês a primeira edição se esgotou.

Ao mesmo tempo, Plinio desenvolvia intensa atividade como jornalista, o que o levou ao terreno da politica. Desenvolveu aí também reflexões sobre o sentido da arte e da literatura, vendo-as como vetores da construção da sociedade nacional e de valores nacionalistas. Junto com Menotti del 
Picchia, Cassiano Ricardo, Cândido Mota Filho e outros, organizou e liderou uma das correntes literárias da época, propondo a "Revoluçāo da Anta" que deveria revalorizar a cultura indigena no panorama brasileiro. Sua dedicação foi tal que se pôs a estudar a lingua tupi.

Quando, em 1930, Vargas chegou ao poder, à testa do movimento armado que, diz-se até hoje, inaugurou o "Brasil moderno", Plínio Salgado era escritor de renome, jornalista reconhecido e deputado estadual pelo Partido Republicano Paulista. Nesta condição, apoiou a candidatura de Júlio Prestes, político paulista e presidente da província, à presidência da República, contra a de Vargas. Prestes venceu as eleições no corrupto sistema eleitoral da República Velha, onde as denúncias de fraude na contagem de votos eram constantes. Desta vez, no entanto, as denúncias catalisaram o descontentamento popular, as inquietaçōes entre muitos militares e as divisões no seio das próprias elites dirigentes. A 3 de outubro, rebeldes sob o comando de Vargas atacavam, às cinco da tarde, o Quartel General do Exército em Porto Alegre. Começava a derrubada do governo do Presidente Washington Luís e o fim da República Velha.

Enquanto os rebeldes conspiravam, Plinio Salgado estava no exterior, numa viagem que, em parte, decidiria o seu destino. Em abril de 1930, seu amigo e correligionário Sousa Aranha convidou-o a ser o preceptor de seu filho - coisa comum na época, em que a formação escolar costumava ser frágil - e para acompanhar a ambos numa viagem ao exterior. Plínio aceitou a oportunidade valiosa, e assim conheceu parte do Oriente Médio e da Europa. O fato mais importante da viagem, segundo ele próprio, foi o mês que passou na Itália, vendo de perto a consolidaçāo do regime fascista, e onde teve um encontro pessoal com Benito Mussolini. Quando chegou no Brasil, em 4 de outubro, um dia, portanto, depois da eclosão do movimento armado liderado por Vargas, estava convencido de que, se o fascismo não era para ser copiado ao pé da letra no Brasil, nosso pais precisava de algo muito parecido. 
Desde o começo de sua carreira política, Plínio Salgado fora crítico em relação aos postulados comunistas, mas também em relação aos princípios liberais. Via no liberalismo uma das fontes da corrupção e da inércia das elites brasileiras, que abandonavam os mais pobres ao laissez-faire, à sua própria sorte. Ao mesmo tempo, esse paradoxal liberalismo oligárquico das elites favorecia a divisão nacional através dos acordos entre os dirigentes regionais, impedindo, na visão dele, a verdadeira integração do país. Veio daí, de reflexões desse tipo, e também do pensamento que contra a fragmentação da pessoa humana - promovida tanto pelo liberalismo como pelo comunismo - se deveria promover a visão do "homem integral", a adoção do nome "Ação Integralista Brasileira" para o movimento que fundaria pouco tempo depois, em 1932, e que o levaria ao ponto culminante de sua carreira política - e também à sua queda logo em seguida. O objetivo do movimento seria promover a redenção da pátria, através da construçāo de um "Estado Integral", que catalisasse o espírito da nação e organizasse a representação das classes.

O movimento integralista cresceu rapidamente no Brasil, em parte devido a sua aliança com movimentos católicos conservadores e com movimentos monarquistas. A ascensão de Hitler na Alemanha deu novo impulso ao movimento. Mas, assinalam historiadores, o Integralismo brasileiro tinha, na prática, mais afinidade com o salazarismo em Portugal, e com o franquismo na Espanha, graças ao seu forte traço católico, do que com os regimes liderados por Hitler e Mussolini. Setores do regime varguista aproximavam-se claramente destes regimes de direita. Em nome do combate ao comunismo, Salgado aproximou-se mais e mais de Vargas. Não poucas vezes, militantes integralistas e comunistas trocaram tiros, ou se envolveram em pancadarias nas ruas, com mortos e feridos. Em 1935, o levante armado organizado pelos comunistas a partir de Natal, no Rio Grande do Norte, e no Rio de Janeiro. aproximou de vez Salgado de Vargas: ele atingiu, assim, o ápice de sua influência. 
Plínio constituiu o movimento, misturando nele aspectos de milícias paramilitares com aspectos de ordem religiosa. Os adeptos usavam camisas verdes, tinham a letra grega sigma por simbolo, faziam saudações com a mão direita erguida e espalmada, como no Fascismo. Sua saudação era um grito em língua tupi moderna: Anauê, um grito de cumprimento e de guerra. Dois integralistas comuns deviam erguer os braços e gritar Anauê uma vez. Os dirigentes, divididos em provinciais e arquiprovinciais, num arremedo de ordem jesuitica, tinham direito a dois Anauês. O dirigente supremo, isto é, o próprio Plínio Salgado, tinha direito a três, e Deus, a quatro, mas só o dirigente supremo podia saudar a divindade em público.

Havia algo de sinistro em tudo isso, mas também, por vezes, de cômico e patético. Um dos jovens adeptos do Integralismo contou, certa vez, ao professor Antonio Candido (que por sua vez repassou-me a história algo anedótica) como resolveu, pelo senso do ridículo, abandonar o movimento. Estava viajando de automóvel pelo interior brasileiro, no caminho da província de Goiás, com mais dois militantes, um deles um arquidirigente, e o motorista. Ao passarem por um ribeirão, o líder perguntou ao motorista qual era o nome da corrente. Ele declarou o nome (que Candido não lembrava mais) e acrescentou que aquele pequeno ribeirão era um dos formadores do grande rio Araguaia que, com o Tocantins, vai desaguar praticamente na foz do Amazonas. O arquilider fez parar o carro, fez os mais jovens formarem em linha junto à margem - "num calor de rachar" disse o depoente - e gritarem o Anauê, de mão erguida, declarando: "Integralistas, saudemos este pequeno ribeirão que vai formar o grande Araguaia, que é um dos rios da unidade nacional!" Segundo o depoente, para ele aquilo foi demais. Na volta, ele deixou o movimento. Entretanto, os outros integralistas passaram a perseguilo como traidor. Numa ocasião, chegaram a trocar tiros com ele. Em outra, conseguiram sequestrá-lo e o espancaram brutalmente por "traição" fato que alcançou grande repercussão política em São Paulo. 
Com esses métodos, Plínio Salgado organizou um verdadeiro Estado paralelo, pronto a tomar o Estado brasileiro. Com efeito, depois da aproximação, o choque com Vargas seria inevitável. Este veio em 1938, no ano seguinte àquele em que Vargas deu o golpe de Estado fundador do Estado Novo, que Plínio, em princípio, apoiou, extinguindo formalmente a AIB como movimento político, em fins de 1937 Em 1938, Vargas deu sinal verde para que os integralistas começassem a ser perseguidos e neutralizados em diversos pontos do pais. Em maio daquele ano, um grupo de integralistas atacou estaçōes de rádio e o próprio palácio presidencial no Rio de Janeiro. Mas estavam tão desorganizados que Vargas, sua familia e mais um pequeno grupo de defensores conseguiram resistir até que o Exército chegasse com reforços. Embora não fosse acusado de participação nesta tentativa fracassada de golpe, Plínio Salgado foi preso em 1939 e deportado para Portugal, onde permaneceu até a queda de Vargas, em 1945. Embora voltasse a ter influência posteriormente, chegando a ser candidato à Presidência da República em 1955, a sua golden age terminara. Depois da volta do exílio, sua atividade política revestiu-se mais e mais de um catolicismo conservador. Algo de seus principios integralistas sobreviveu no regime imposto pelos militares a partir de 1964, que ele, como já disse, apoiou, tornando-se um dos grandes defensores da censura à imprensa e aos meios intelectuais, para "disciplinar" a nação.

Foi no período de sua ascensão política, e como parte dela, que Plinio Salgado escreveu e publicou seus quatro romances: O Estrangeiro (1926); O Esperado (escrito em 1930, em Paris, e publicado em 1931); O Cavaleiro de Itararé (1933); e A Voz do Oeste (1934), romance histórico e, de longe, o pior de todos. Os outros três alternam momentos de fragilidade na construção com momentos de excelente prosa - alguns brilhantes - sobretudo se os virmos como uma composição da mistura fragmentária de pontos de vista, caracteristica dos estilos modernistas, com uma crônica da vida paulista, paulistana e brasileira, num estilo bem tradicional cuja ori- 
gem remonta às velhas crônicas medievais portuguesas. O estilo de Plinio apresenta também sinais de leituras naturalistas, como a de Eça de Gueirós, e de um certo gosto por atmosferas melodramáticas e românticas.

Com estes ingredientes Plínio Salgado conseguiu traçar retratos muito vividos e críticos da sociedade brasileira, sobretudo a de São Paulo, e dos processos de transformação por que o país, o estado e a cidade passavam: as levas recentes de imigrantes davam novos perfis ao velho Brasil de raiz lusitana e ao mundo rural caipira, e nas cidades a industrialização mudava a paisagem física e humana. A busca febril de novidades cosmopolitas e de um estilo de vida sofisticado pelas classes ricas e emergentes se contrapunha à crescente pauperização dos bairros periféricos. Tudo isso Plínio Salgado pintou com cores muito expressivas.

Se teve seu forte na pintura dos quadros sociais e na psicologia das relaçōes humanas neste quadro de transformações, Plínio Salgado encontrou seu Waterloo literário no desenho de protagonistas consistentes e, sobretudo, no desfecho de seus enredos. Tinha ele um afã político de desenhar quadros não apenas expressivos, mas modelares para a sociedade nacional em transformação. Seus personagens, enquanto se mantinham numa visão exterior de seus movimentos, num mundo social conturbado, exprimiam de modo convincente as alteraçōes em processo na paisagem social. Mas, quando vistos de modo isolado, nas profundezas de suas almas, começavam a resvalar para estereótipos que deveriam encarnar idéias abstratas sobre o ser humano. Como resultado, à medida que os enredos avançavam, as opçōes, as escolhas, os atos dos personagens começavam a assumir um certo tom artificial. Plínio Salgado jamais conseguiu dar, por exemplo, um desenlace convincente para os enredos amorosos em que seus personagens se envolviam; um certo tom moralista de melodrama ou folhetim antigos terminava por recobrir as situações a que chegavam. Somava-se a isto o desejo evidente por traçar pai- 
néis completos da sociedade nacional. Há uma abundância de personagens nos romances de Plinio Salgado: neles há pelo menos uma vintena de protagonistas, dezenas de coadjuvantes e centenas, senão milhares de figurantes. $O$ que poderia ser um impulso para a análise social segundo o modelo de Balzac, transformava-se numa espécie de ópera grandiloquente que tendia ao exagero e à demasia.

Algo destas tendências se espelhava nos prefácios que sempre acompanhavam os romances, e nas classificações com que o autor procurava enquadrá-los. O Estrangeiro, por exemplo, era apresentado como uma "crônica da vida paulista" e o prefácio dizia:

"Este livro procura fixar aspectos da vida paulista nos últimos dez anos. Vida rural, vida provinciana e vida na grande urbs. Ciclo ascendente dos colonos (os Mondolfis); ciclo descendente das raças antigas (os Pantojos). Marcha do caboclo para o sertão e novo bandeirismo (Zé Candinho); deslocamento do imigrante nas suas pegadas e novo periodo agricola (Humberto) (...)" etc.

Deste modo, o autor vai esboçando cada um de seus personagens ou grupos de personagens como tipos vetoriais da nova paisagem nacional em debuxo.

O segundo romance, O Esperado, é o de subtitulo mais lacônico: apresenta-se como um "romance", simplesmente. Mas, na abertura, diz o autor:

Passam, através deste livro, os Inquietos, os Inadaptados. Passam vitimas e opressores. Chocam-se direções contrárias do Pensamento. É o drama do nosso Espirito. Onde não há culpados. Onde tudo é incompreensão.

Depois ele diz:

"Este romance não defende nenhuma tese" 
Respeitando-se o autor quanto à sinceridade de seus propósitos, pode-se dizer que essa afirmaçāo não é verdadeira. O romance defende não uma, mas várias teses: a de que os homens têm um destino pré-traçado em seus caracteres; a de que estes são o resultado do meio em que vivem e da cultura que trazem do berço. Estas duas teses dão ao pensamento de Plínio um ressaibo positivista, comum no naturalismo brasileiro e português. Além destas duas, o romance, pelo título, deixa antever a tese de que somente o advento de um líder providencial pode tirar a nação de seus impasses, espelhados nas páginas finais da narrativa, num grande confronto entre forças políticas antagônicas, mais a polícia, no centro de São Paulo, em meio a uma tempestade.

Este "Esperado" era um tema presente na sociedade brasileira de então. Paulo Prado, um dos intelectuais mais expressivos daquele momento, termina seu Retrato do Brasil, de 1928, falando neste líder que fazia falta para libertar o país do marasmo melancólico a que o condenaram as "três raças tristes" que o formaram: os portugueses expatriados, os negros escravizados e os indios exilados em sua própria terra, depois da colonização. O topos do "Salvador da Pátria" foi e é recorrente na política brasileira. Suas origens remontam ao velho sebastianismo luso.

Quem seria este "Esperado"? A visão do romance em seu contexto imediato, escrito em 1930 e publicado em 1931, permite supor que, para Plínio, a chegada de Vargas ao proscênio da política brasileira apontava o advento do lider providencial. Mas o tipo de liderança que ele desenvolveu depois. na Ação Integralista Brasileira, permite supor que ele se convenceu de que o "Esperado" seria ele mesmo, Plínio Salgado.

No prefácio deste romance, Plínio já anunciava o próximo, O Cavaleiro de Itararé:

Pertence [este romance] à série de crónicas da vida brasileira contemporânea, que começaram com O Estrangeiro. que se desdobraram diante do panorama mais complexo 
de O Esperado, e que continuarão, possivelmente no terceiro marco de nossa marcha, que será O Cavaleiro de Itararé.

Publicado em 1933, este terceiro romance tinha por motivo de seu título uma lenda do sul do estado de São Paulo, da região montanhosa de Itararé, segundo a qual, em certas noites, a morte passa a cavalo pelos campos, semeando destruição. Embora planejado antes, não se pode deixar de associar o romance e seu título à decepção de Plínio com Vargas. No prefácio, diz ele que o romance foi escrito "em horas amargas de desilusão" Em 1932 houvera um levante militar em São Paulo, contra o governo de Vargas. O levante fora provocado por uma mistura da decepção com o novo regime, que não implementava rapidamente as reformas que anunciara, com um esforço restaurador das velhas oligarquias agrárias de São Paulo, que viam seu poder esvaziado e a quem desagradava a nova politica trabalhista, esboçada por Lindolfo Collor. O levante foi sufocado em poucos meses de luta. Plínio Salgado manteve-se distante dos rebeldes de 32 , mas não escondia sua insatisfação com o regime de Vargas por sua demora em promover as esperadas reformas que, para ele, deveriam ter um caráter doutrinário exemplar no sentido da salvação e do reerguimento nacionais.

"Itararé" tornou-se um signo de identificação do novo regime e de sua politica de compromissos com a velha ordem. Quando as tropas comandadas por Vargas tomaram o rumo do norte, para ocupar o Rio de Janeiro. que então era a capital da república, esperava-se que a grande batalha entre os rebeldes e os legalistas se daria no Passo de Itararé, na divisa entre os estados do Paraná e de São Paulo, uma região pobre e abandonada. Entretanto, cientes de sua posição fragilizada, o Comando das Forças Armadas depôs o presidente Washington Luis e entregou o poder a Vargas. "Itararé" ficou na história brasileira como "a batalha que não houve" Houve até um célebre escritor cômico brasileiro, de grande sucesso na épo- 
ca, Aparício Torelly. que se autonomeou o "Barão de Itararé" passando a assinar suas obras sempre irônicas e satíricas com este pseudônimo. Hoje ele é mais conhecido por seu apelido do que por seu nome de batismo.

É inevitável, portanto, que se pense em Vargas como o malfadado cavaleiro a que o terceiro romance se referia. Acresce, ainda, que Plínio, no prefácio, dizia que o romance era um chamado aos jovens e aos militares do pais para que cumprissem o dever de salvar a pátria. E ele terminava com dizeres mais de orador que de escritor:

Porque, se a juventude, civil e militar, nāo assume um papel decisivo; se continuarmos a assistir, de braços cruzados, à confusão dos espíritos, ao jogo das intrigas, ao desencadear das ambiçōes dos mil grupos que desarticulam a opinião nacional. então nada mais resta a tentar pela salvação do Brasil.

O quarto e último romance, $A$ Voz do Oeste, publicado em 1934, é apresentado como um "romance-poema da época das Bandeiras" E, no prefácio, diz o autor: "A história que vai ser narrada, nos sucessivos capitulos deste livro, é a história da alma brasileira, no alvorecer dos primeiros impulsos da Nação"

O romance enaltece "a mitologia do selvagem americano" porque ela explica "a colaboração misteriosa da Terra nos grandes dramas brasileiros que os séculos sepultaram" o que mistura retórica romântica com determinismo de raiz positivista. O romance narra as aventuras de uma bandeira que, a partir de São Paulo, mergulha no sertão americano até o sopé dos Andes, animada pelo propósito secreto de encontrar El-Rei D. Sebastião, o monarca português desaparecido na Batalha de Alcácer-Quibir, no norte da África, em 1578. O rei, por misteriosos caminhos e razões, estaria prisioneiro em algum lugar da Cordilheira dos Andes, próximo às minas de Potosí, na atual Bolivia. 
A idéia geral é a de expor que, desde o tempo das antigas raças que habitavam o Brasil, este já estava predestinado a ser uma grande nação. Como se vê, o romance se afasta da visão regular do nazismo, da determinação do destino dos povos pela superioridade ou inferioridade racial, fazendo o elogio de uma raça e de uma cultura que, na escala nazista, não seria valorizada. Do fascismo retém a componente grandiosa, o tom grandiloquente que, aliás, torna desagradável a sua leitura, e o sentido de determinação histórica, de grandeza da pátria. Mas chama em sua defesa o velho misticismo sebastianista nascido da crise portuguesa dos fins do século XVI.

Este misticismo fora lembrado por vários intelectuais, entre os quais Euclides da Cunha, em Os sertōes, de 1902, para explicar as revoltas camponesas brasileiras, entre elas a de Canudos. A Voz do Oeste reúne este misticismo de raiz lusa com uma visão das raças indigenas como motivadas por um sentido místico de integração numa civilização maior e superior: a brasileira, que Plínio identificava como matriz da "quarta humanidade" Mas o todo não convence: Plínio não consegue criar personagens históricos convincentes, seus indios parecem mais figurantes de alguma ópera burlesca, e o romance termina literalmente abandonando seus personagens à própria sorte, em troca da visão grandiosa de uma miragem: nas encostas das montanhas alcantiladas resplandece uma cidade descrita como "colossal e imponente" Esta cidade é, ao mesmo tempo, do passado e do futuro, pois, diz o narrador, "para o espírito não existe o tempo" E o autor aproveita a oportunidade para se despedir de seus personagens: "Que importa, de agora em diante, o destino de Martinho e de D. Gonçalo? Que mais interessa El-Rey. o Encoberto? Ou o descobrimento de Violante? Ou o encontro da virgem tupi e das cavernas de ouro?"

A Voz do Oeste dá a impressão de ter sido um romance que, depois de começado, tornou-se um problema para o autor, premido cada vez mais pela cena política complexa em 
que ele e o Brasil mergulhavam. E ele, então, terminou-o às pressas, podando a vida dos personagens.

Os romances anteriores reservam melhores páginas ao leitor.

De todos o mais inovador do ponto de vista do estilo é $O$ Estrangeiro. É escrito numa sucessão de fragmentos, que apreendem momentos, situações, estados de espírito. Vez por outra escorrega para o aforismo ou para a reflexão abstrata. Entretanto, essa inovação não esconde a concepção melodramática do enredo. O estrangeiro do título é um imigrante russo, Ivan. É um refugiado político, que teve seu grande amor negado na terra pátria. Consegue entrar no Brasil, cujo governo fazia uma cuidadosa triagem ideológica entre os imigrantes, em meio a um grupo de imigrantes italianos.

O romance se divide em duas partes bem caracterizadas. Na primeira, Ivan vai para o interior, para as fazendas de café, onde assiste à decadência das familias tradicionais, constata a miséria dos camponeses (caipiras) brasileiros, abandonados pelos governos, e a prosperidade dos recém-chegados. Na segunda, ele vem para a cidade grande, a metrópole São Paulo, onde abre uma fábrica e enriquece. Vive, então, como industrial próspero numa cidade cosmopolita, que perdeu o contato com as antigas raizes culturais do país e da região. Reconhece, apesar de ser bem aceito na sociedade, que, distante do seu país de origem, levando o peso daquele amor insatisfeito, incapaz de desenvolver novas raizes, será sempre um estrangeiro, um apátrida. Para complicar sua situação psicológica, a consolidação dos sovietes em sua pátria, depois da Revolução de 1917 traz para o Brasil levas de imigrantes que rejeitam o comunismo. Ivan sonha com a possibilidade de encontrar, entre estes imigrantes, sua amada Ana. descendente de uma familia aristocrática.

O final é patético. Ivan pensa reconhecer entre alguns refugiados que vêm pedir emprego em sua fábrica a sua adorada Ana. É noite de Ano Bom, e haverá uma grande festa na 
fábrica. Planeja, então, envenenar todos, colocando uma droga poderosa na cerveja que é servida. Fecha-se com a jovem que, na verdade, não é Ana - no terraço, onde ambos morrem. A conclusão que se tira é que a falta de uma pátria enlouquece o homem, e que esta condição ameaça a sociedade brasileira, arriscada de se distanciar de suas raizes tradicionais sem se consolidar com um espírito de "união nacional" $\mathrm{O}$ romance reserva ainda uma surpresa: os capitulos finais revelam que é um dos personagens, Juvêncio, um mestre-escola nacionalista, que está escrevendo a narrativa, enquanto marcha para o sertão em busca das raizes da pátria.

$O$ Esperado contém algumas das melhores páginas de Plínio Salgado no sentido social. O protagonista é o personagem Edmundo Milhomens que, tentando sobreviver entre a metrópole inovadora e o sertão tradicional, testemunha os novos processos sociais e políticos que, ao mesmo tempo, arrastam e dividem a nação. Merecem atenção especial. por exemplo, os capítulos XXV (“O Êxodo") e XXIX ("Péo! Péo!"). No primeiro, Plínio relata a situação premente dos caipiras desalojados impiedosamente de suas terras pelas disputas políticas entre lideres de partidos opostos, e forçados a marchar para o oeste. Neste processo, desbravam novas terras, que depois serão novamente ocupadas por políticos e proprietários das cidades, num processo doloroso e sem fim e que foi o processo de ocupação das terras de São Paulo. No segundo, através do jogo entre os personagens, Plínio expõe duas teorias sobre o trato policial dos prisioneiros políticos. Um dos policiais acha melhor convencer os jovens revolucionários da inutilidade de suas idéias através da persuasāo, enquanto o outro entende que o melhor é mesmo abalar-lhes o moral pela pancadaria.

Este romance revela a tendência do autor para complicar seus enredos pela multiplicação dos personagens. E termina com uma visão fantástica, de uma batalha no escuro entre forças políticas antagônicas, no centro de São Paulo. Só 
a chegada do Grande Líder, o Esperado, poderá salvar esta sociedade ameaçada de desagregação.

Finalmente, O Cavaleiro de Itararé faz uma crônica muito interessante do mundo das classes dirigentes de São Paulo, do começo do século XX até o começo da década de 30 . Tem de tudo: troca de bebês, revelaçōes de identidade, conspirações, comédia e tragédia social, melodrama e drama amoroso. Dois dos protagonistas (pois são vários) são Urbano e Teodorico, as crianças trocadas. O primeiro, filho de uma familia rica, cresce entre pobres - e torna-se dono de um caráter exemplar. O segundo, filho da família pobre, cresce entre os ricos, e carece de melhores qualidades morais. No final, depois de voltas e reviravoltas, Urbano impede que Teodorico e seu irmão Pedrinho (que era filho da familia que criara Urbano, sendo, na verdade, irmão de Teodorico) se matem a tiros por causa da jovem Elisa, que ambos desejam. Mas Urbano, ferido, morre. O resultado é previsível: a jovem se deixa conquistar pela memória do herói morto, não casando com nenhum dos pretendentes, o que, na verdade, apenas ratifica o moralismo do autor.

Esses enredos melodramáticos não impedem a percepção de que Plínio traçou painéis muitos interessantes das transformações por que passava a sociedade brasileira. Dois aspectos ainda merecem comentários. Em O Cavaleiro de Itararé há um personagem judeu - Gruber - no primeiro plano. É um revolucionário e anarquista, mas sem caráter. Age dessa forma menos por convicção do que por compulsão. Plínio esboça a tese de que os judeus, privados de uma pátria e destituídos de uma nação, não podem ter caráter coletivo que dê consistència ao caráter individual. Pesa, portanto, em seu julgamento negativo sobre este personagem, menos a questão racial e mais a cultural, embora também carregada de preconceito inaceitável. 


\section{CONClusĀo}

Fiz uma experiência, apresentando páginas de Plínio Salgado - sobretudo aqueles capítulos de O Esperado, em que a questão social avulta, a colegas meus, professores de Letras, pedindo-lhes que identificassem o autor. Responderamme todos os consultados que deveria ser um autor dos anos 20 ou 30, de esquerda. A surpresa, ao tomarem conhecimento de quem se tratava, confirma o fato de que, se Plinio não conseguiu ser $O$ Esperado na política brasileira, ele é ainda hoje um escritor surpreendente, inesperado. Não precisamos - não devemos - concordar com seus preconceitos e com seu conservadorismo reacionário. Mas, na esteira da citação de Marx/Terêncio que nos serviu de epígrafe, não podemos - não devemos - ignorá-lo.

\section{BiBLIOGRAFIA:}

Brandi, Paulo/Soares, Leda - "Plínio Salgado" In Enciclopédia Brasileira. 1930 - 1983. Rio de Janeiro: Fundaçāo Getúlio Vargas s/d. 4\%. volume. Págs. 3051 - 3061.

Salgado, Plinio. O estrangeiro. São Paulo: Helios, 1926. $2^{\mathrm{a}}$. ed. ed.

. O esperado. São Paulo: Companhia Editora Nacional, 1931. $1^{\text {a }}$.

O cavaleiro de Itararé. São Paulo: Unitas, 1933. $1^{a}$. ed.

A Voz do Oeste. Rio de Janeiro: José Olympio, 1936. $1^{\text {a }}$ ed.

Trindade, Hélgio - Integralismo. O Fascismo brasileiro na década de 30. Porto Alegre: Difel/UFRGS, 1979.

Vasconcellos, Gilberto - Ideologia curupira. Análise do discurso integralista. São Paulo: Brasiliense. 1979.

ABSTRACT: This article describes, in the first place, the biography and the political activities of Plinio Salgado, the leader of Brazilian fascist inclined movement called Integralismo. Later, it describes and analyses his four novels, within the frame of the Brazilian Literature in the 30's, and what role they had played within the author's political 
Lingua e Literatura. n. 29. p. 51 -69. 2007-09.

project. It also analyses the author's social criticism of the brazilian society at that time.

Keywords: Plinio Salgado; novel; Integralism 